\title{
The EUFAS European Addiction Research Award 2020
}

Since 2016, EUFAS collaborates with the journal European Addiction Research to present the EUFAS EAR Award to an outstanding scientist in addiction research.

The EUFAS EAR Award nomination committee (Antoni Gual [Chair of the Committee], Jørgen G. Bramness, Falk Kiefer, and Anneke Goudriaan) has suggested that the EUFAS EAR Award 2020 be awarded to Professor Marta Torrens. Professor Torrens is the Head of the Addiction Program at the Institute of Neuropsychiatry and Addictions-Parc de Salut Mar, Barcelona, Professor of Psychiatry at Universitat Autònoma de Barcelona and Universitat de Vic-CC, in Spain, and Executive Member of the Section on Dual Disorders/Pathology of WPA. The nomination was endorsed by the EC of EUFAS and the EAR.

Professor Marta Torrens is awarded the EUFAS EAR price 2020 for excellent contributions to European addiction research. Through her numerous publications (> 200) in international referee-based journals of the highest quality, Torrens has contributed substantially to European addiction research, in both basic and clinical research. Her main lines of research are assessment and treatment of opioid, alcohol, cocaine, cannabis, novel psychoactive substance, related disorders; gender perspective in addiction; diagnosis and treatment of medical (HIV and HCV infections) and psychiatric (design and validation of instruments for the screening and diagnosis, biomarkers and treatment) comorbidities. In the latter, she had a central role in the introduction of European versions of psychometric screening and diagnostic instruments like the DDSI and PRISM. She has participated in many national and international conferences and
Professor Marta Torrens

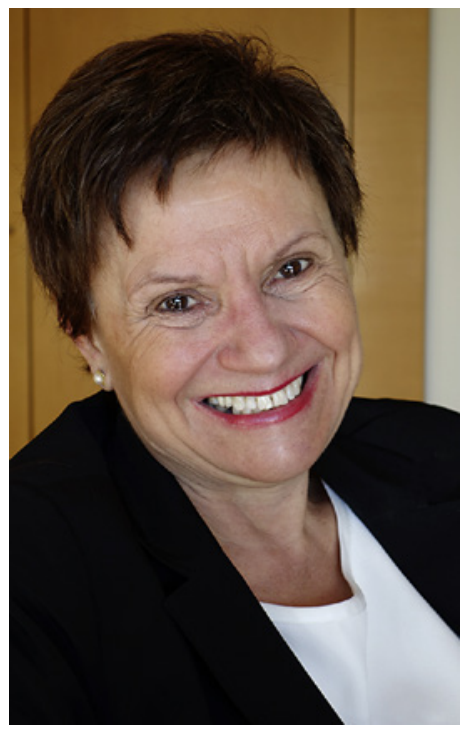

courses about good practices in the clinical treatment of drug-related disorders. She has collaborated with international organizations such as the EMCDDA, WHO and UNODC and has been invited as an expert to scientific congresses and meetings.

\section{Former Recipients of the EUFAS EAR Award}

- 2016 Professor Karl Mann

- 2017 Professor Jürgen Rehm

- 2018 Professor Wim van den Brink

- 2019 Professor John Strang

- 2020 Professor Marta Torrens 